\title{
LONG TERM EVALUATION OF NON-SUBMERGED IMMEDIATE IM- PLANTS WITH EARLY LOADING IN FRESH EXTRACTION SOCKET OF SINGLE ROOTED TEETH
}

\author{
Abdelmageed H. Alfakhrany* and Mohammad A. A. Shuman**
}

\begin{abstract}
The purpose of this study was to evaluate long-term stability and tissue integration of non-submerged immediate implant placement with early loading. Patients and methods: Fifty-five immediate implants (2 parts) were inserted in 30 patients, (17 males has 35 implants and 13 females with 20 implants). The patient's age ranged from 22 to $55 \mathrm{y}$. with mean of $38.08 \pm 10.18$. These implants were placed in fresh extraction sockets of maxillary and mandibular single rooted teeth, (40 implants in aesthetic zone and 15 implants in premolar region). Clinical and radiographic evaluation were done immediately, 1 and 10 weeks, 6 months, and once yearly for 4 years after implant insertion. Postoperative evaluation was done to assess pain, peri-implantitis, probing depth (PD) and plaque index(PLI). In addition, bleeding index(BI) and distance between implant shoulder and mucosal margin(DIM) were assessed. Primary and seating torque, percussion test and ISQ were done to assess stability of the implants immediately and 10 weeks. Crestal bone level and bone density was assessed radiographically with parallel cone technique using digital IOPA and CBCT. After 10 weeks, implant were tested for stability with torque at $35 \mathrm{Ncm}$ and with Osstell, and a final prosthesis were inserted. Results: All implants were stable and osseointegrated without any mobility, at the time of abutment placement but 2 implants get stable after 6 months. Four patients ( 5 implants) were missed after 3 months from prosthetic insertion. Radiographic examination showed only $0.5-1 \mathrm{~mm}$ marginal bone loss around the implants. Clinically, good, successful results were detected with assessment of plaque and bleeding indices, gingival rescession and probing depth. Conclusion: Non-submerged immediate implants can be placed successfully with good tissue integration in fresh extraction socket and can be early loaded without bone graft to fill gap around non-submerged implants.
\end{abstract}

\section{INTRODUCTION}

Teeth replacement with an implant is a complex surgical procedure, mainly due to alveolar ridge resorption, that follow tooth extraction ${ }^{(1)}$. Following extraction, there are a series of biological processes such as; vertical and horizontal bone resorption, with a change in height and thickness of the alveolar bone. This resorption is a physiologic process which cannot be easily prevented ${ }^{(2)}$. Uncontrolled alveolar bone resorption may lead to severe bone deficiency, and may even contraindicate to an implant insertion ${ }^{(3)}$.

Many approaches have been used to preserve alveolar bone after teeth extraction ${ }^{(1)}$. Immediate implant insertion in fresh extracted socket was considered as one of the approaches for preserving bone volume ${ }^{(4)}$ So that, a risk of unacceptable loss of vestibular bone height and overlying soft tissue can be prevented ${ }^{(5)}$. This type of implant is safe and good modality for rehabilitation of partially, ${ }^{(6)}$ and fully edentulous patient ${ }^{(7,8)}$ Immediate implant placement has many advantages, it reduces morbidity, decrease waiting time and number of necessary surgeries and allows placement of implant in an ideal position ${ }^{(9)}$ Also, patients satisfaction and preservation of crestal bone height was observed with this type of implant ${ }^{(10)}$

\footnotetext{
*Assist Prof.,Departement of Oral \& Maxillofacial Surgery Al- Azhar University, Cairo, Boys.

** Assist. Prof., Departement of Oral \& Maxillofacial Surgery Al-Azhar University Assiut Branch.
} 
Recent experimental and clinical studies aimed to progressive shortening of the healing period with immediate loading ${ }^{(11)}$ These benefits may come at a cost, increased risk of infection, the need for bone augmentation procedures to solve the disturbances between implant surface and alveolar bone, and significant risk of aesthetic complications ${ }^{(12)}$ Initial stability of an immediate implant depends on anchorage to a small part of 3 to $5 \mathrm{~mm}$ sub apical alveolar bone. Also, the size of the peri-implant bone defect (horizontal defect dimension) has effect on the amount of bone-implant contact area ${ }^{130}$

To obtain osseointegration, and to eliminate infection and gingival down-growth and to provide healing without loading force to implant, submerging implant underneath a mucosal tissues was required $^{(14,15)}$ In contrast, submerging implant was not considered a prerequisite for tissue integration by the international Team for Oral Implantology (ITI) ${ }^{(16)}$ Bone to implant contact as well as the density of the peri-implant bone was similar in the submerged and non-submerged groups. So that a non-submerged installation technique may provide conditions for tissue integration similar to those obtained from using of a submerged approach ${ }^{(17)}$

Non-submerged implant has a considerable success in different clinical centers ${ }^{18)}$.The success of a single phase surgery implant not only determined by a high percentage of survival but also by an acceptable quality of survival ${ }^{(19)}$ The aim of this study was to evaluate, long standing implant stability and consequently, the success of the immediate, non-submerged implant via a fresh extraction socket, with early loading.

\section{PATIENTS AND METHODS}

Fifty-five immediate non-submerged, Zimmer (Tapered, Swiss Plus,USA) implants were placed into fresh extraction sockets of thirty patients, between 2006 and 2014. Male patients were 17 (56, $67 \%)$ with 35 implant $(63.63 \%)$. Female patients were $13(43.33 \%)$, has $20(36.37 \%)$ implants. The patient's age ranged from 22 to 55 years with mean of $38.08 \pm 10.18$ years (Tab. 1 ).

TAB.(1) Showing; Age, sex and number of patients and implants.

\begin{tabular}{|l|l|l|l|}
\hline \multicolumn{1}{|c|}{ Factor } & Categories & Patients No. & Implants No. \\
\hline Number & & $30(100 \%)$ & $55(100 \%)$ \\
\hline Sex & Male & $17(56,67 \%)$ & $35(63.63 \%)$ \\
& Female & $13(43.33 \%)$ & $20(36.37 \%)$ \\
\hline Age range; 22-55y. & $<36$ & $11(36.67 \%)$ & $20(36.36)$ \\
Means SD; & $36-45$ & $10(33.33)$ & $20(36.36)$ \\
$38.08 \pm 10.18$ & $>45$ & $9(30,00)$ & $15(27.28)$ \\
\hline
\end{tabular}

This study was carried out on selected patients according to well-defined inclusion and exclusion criteria. The patients were included have bone quality of either type 2 or 3 according digital preoperative $\mathrm{x}$-ray. They should have adequate bone height apical to extraction socket (3 to $5 \mathrm{~mm}$ to provide initial implant stability). Buccolingual and mesiodistal dimension of alveolar crest more than $6 \mathrm{~mm}$ to allow placement of at least a $3.7 \times 10 \mathrm{~mm}$ implant. In addition, a normal to thick flat gingival biotype ( $2 \mathrm{~mm}$ at least), presence of single rooted non-restorable tooth and good oral hygiene should be encountered.

The site of implants were in maxillary and mandibular incisors, canine and single rooted premolars. The cause of extractions were root fractured, grossly carious with endodontic failure and periodontal compromised teeth, which could not be treated with restorative procedures or periodontal surgery(Tab.2). 
TABLE (2): Showing; Location, site of implant and causes of teeth loss.

\begin{tabular}{|c|c|c|}
\hline Factor & Categories & No. \\
\hline \multirow{2}{*}{ Location of implant } & Maxilla & $34(61.82 \%)$ \\
& Mandibular & $21(38.18 \%)$ \\
\hline \multirow{2}{*}{ Tooth type } & Central incisor & $17(30.91 \%)$ \\
& Lateral incisor & $8(14.55 \%)$ \\
& Canine & $15(27.27 \%)$ \\
& Premolar & $15(27.27 \%)$ \\
\hline \multirow{2}{*}{ Cause of loss } & Periodontal & $25(45.45 \%)$ \\
& Destruction & $30(54.55 \%)$ \\
\hline
\end{tabular}

Patients excluded from this study were those with uncontrolled systemic disease, untreated periodontal disease, heavy smoking, bruxism, loss of labial crest of bone after extraction (fenestration and dehiscence) and inadequate mouth opening $(<4 \mathrm{~cm})$. Also the patients with presence of active infection and insufficient interocclusal space to accommodate prosthetic component were excluded.

Bone qualities of selected patients were; type 2 in $40(72.73 \%)$ and type 3 in $15(27.27 \%)$. Implant lengths were $10,12 \& 14 \mathrm{~mm}$ and with diameters of; 3.7, $4.1 \& 4.8 \mathrm{~mm}$. (Tab. 3).

TABLE (3). Showing; Bone type, implant fixtures length and diameter

\begin{tabular}{|c|c|c|}
\hline Factor & Bone Quality & No. \\
\hline \multirow{2}{*}{ Bone type } & 2 & $40(72.73 \%)$ \\
& 3 & $15(27.27 \%)$ \\
\hline \multirow{2}{*}{ Implant length } & $10 \mathrm{~mm}$ & $4(7.27 \%)$ \\
& $14 \mathrm{~mm}$ & $36(65.45 \%)$ \\
& $3.7 \mathrm{~mm}$ & $15(27.27 \%)$ \\
\hline \multirow{2}{*}{ Implant diameter } & $4.1 \mathrm{~mm}$ & $26(38.18 \%)$ \\
& $4.8 \mathrm{~mm}$ & $8(14.55 \%)$ \\
\hline
\end{tabular}

Each patient signed an informed consent after having details about the procedures before starting of the study.

\section{Preoperative preparation}

Amoxicillin with clavulanic acid was administered, one hour before surgery and then twice daily for 6 days. The patient is then draped completely, except the operative site. The oral cavity is prepared for the procedure with copious irrigation and brushing with chlorhexidine $0.2 \%$ to decrease the bacterial contamination.

\section{Surgical protocol}

Local anesthesia was injected and a careful teeth extractions were done, atraumatically as possible, followed by alveolar curettage and irrigation to remove any granulation tissue that might be present $^{(11)}$. Implant fixtures were inserted after careful drilling and preparation of the implant bed. The sequence of drilling was carried out depending upon the type of bone, starting with a pilot drill with slow speed (500 rpm). Drilling extended $4 \mathrm{~mm}$ beyond the apex of socket under copious internal and external cooling ${ }^{(20)}$ The implant was inserted with hand torque ratchet to enabled assessment of implant insertion torque values. Minimum insertion torque values of 35 Newton-centimeters $(\mathrm{Ncm})$ indicated adequate primary stability for the implant. Also sound was listened and recorded after implant insertion. Primary stability evaluated with insertion torque measured in $\mathrm{Ncm}$ and resonance frequency analysis (RFA) measured by Osstell machine (21) Temporary healing screw covered fixtures, which were replaced with permanent restorations, after assessment of secondary stability (Fig.1).

Routine postoperative instructions of rinsing, maintaining of oral hygiene and antibiotic administration were given to all patients. 


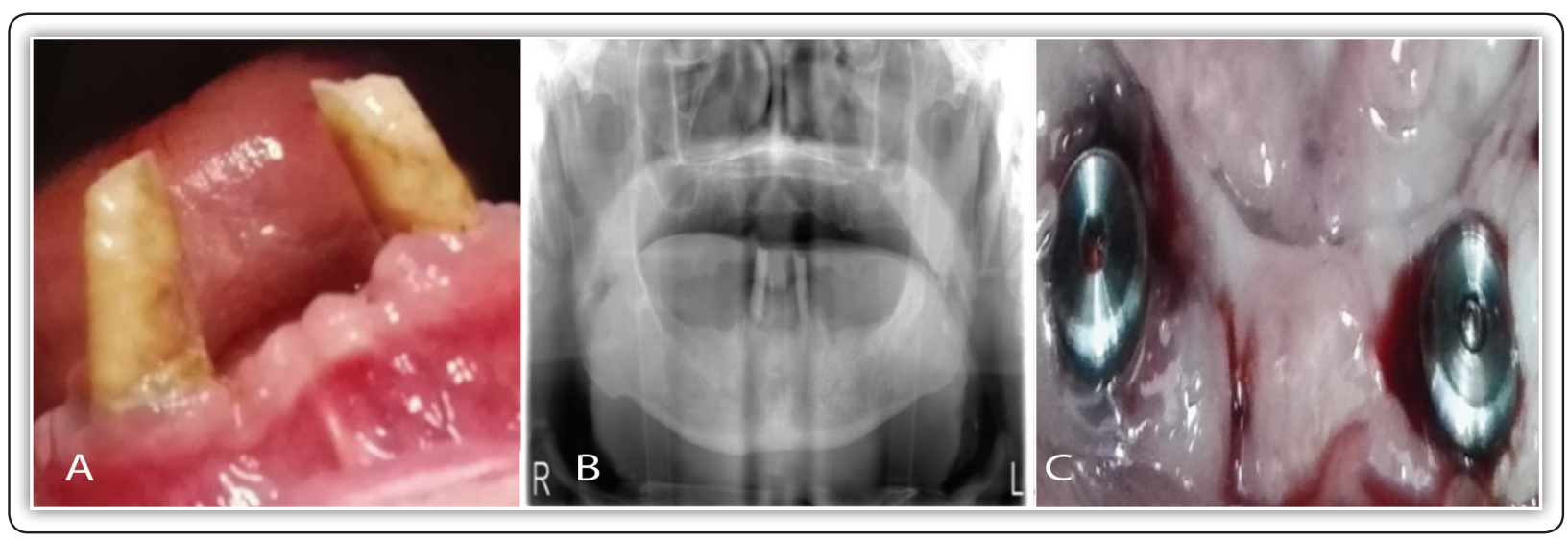

FIG (1) Showing; Preoperative photographs and x-ray of canine teeth(A\&B) and implant insertion covered with temporary screw (C).

\section{Post-operative assessment}

I. Resonance Frequency Analysis (RFA); it is a testing method of lateral micro- mobility and stability of implant ${ }^{(21)}$ After attachment of transductor (Smart beg) to implant fixture, Osstell was used, immediately and at 10 weeks post implant insertion, to measure this frequency at buccal, lingual, mesial and distal direction and take the median of them. Measurement unit is Implant Stability Quotient (ISQ). Implant stability determined for implant with an ISQ of 47. If ISQ is 49 , the implant left to heal for 3 months. More than 54 refers to osseointegrated implant and loaded was done immediately.

II. Insertion and Seating torque; at $35 \mathrm{Ncm}$ were done immediately after implant insertion and at 10 weeks just before permanent restoration. This method gave information about primary and secondary stability of the implant, respectively ${ }^{(20)}$

III. Percusion sound; was listening with tapping the implant with mirror handle. Ringing tone sound indicating good osseointegration, while dull sound refers to bad osseointegration.

IV. Standardized digital periapical radiographs (using RVG), were taken with long-cone parallel technique, with customized film holder at 1 and 10 weeks, 6 months and 4 years. Also, cone beam CT was done at 10 weeks and 4 years to assess alveolar bone level around implant (distance between implant shoulder and first observing highest of bone crest, at mesial and distal site and medium of them was taken). Radiolucency was observed to determine extent of peri-implant crestal resorption. In addition, bone density (BD) was assessed, in Hounsfield unit, at 4 interested points and the median of them was taken ${ }^{(22)}$

V. Clinical evaluation was done in periods as same as radiographs, to assess the following indices on 4 surfaces of the implants and mean value of them was taken and recorded ${ }^{(12)}$

1. Plaque index, (PLI), with the following; Score: 0, plaques not detect, Score: 1, plaque recognized only with probe across marginal Surface of the implant, Score: 2 , plaque can be seen by the naked eye, while in Score; 3, excessive soft matter observed.

2. Bleeding index (BI), assessed as in aforementioned surfaces, where, Score: 0, no bleeding when a periodontal probe passed along the gingival margin of implant, Score: 1, Isolated bleeding spot visible. In Score: 2, blood observed as a red line on margins, while in Score; 3 , heavy or profuse bleeding recognized. 
3. Probing depth (PD), measured to the nearest $\mathrm{mm}$ with periodontal probe.

4. Distance between implant shoulder and mucosal margin (DIM), measured to the nearest $\mathrm{mm}$ with periodontal probe at the same surfaces. Negative value recorded in presence of sub gingival implant shoulder.

5. Pain \& satisfaction assessed and recorded; in Visual Analogic Scale (VAS of 10) after implant insertion at whole period of study, to assess the level of satisfaction expressed by each patient.

\section{Statistical Analysis}

Implant stability was evaluated for possible influential factors i.e. age, sex, implant location, length and its diameter, bone type, cause of tooth loss and its type. PLI, BI, (ordinal data) as well as pain (scale data lacked normality) were analyzed by non-parametric methods. These included MannWhitney U test (2 groups) or Kruskal-Wallis test followed by Dunn's test for pairwise comparisons (>2 groups). Normally distributed variables of (DIB), ISQ, PD, DIM and bone density were analyzed parametrically with a repeated measures analysis of variance and Tukey-Kramer test for mean comparison. For presentation, means and standard deviations (SD) were calculated for continuous variables, and median and ranges for ordinal variables. All analyses were conducted using the statistical analysis system, SAS Version 9.10 (SAS Institute Inc., Cary, NC, USA). Significance level was set at $\mathrm{P}<$ or $=0.05$.

\section{RESULTS}

Fifty -five implant fixtures were inserted in 30 patients of this study. Single crowns were done in 16 patients (24 implants) and fixed bridges were done in 14 patients (31 implants). The patients complained of pain and discomfort during the first day of implant insertion. Pain was decreased at the second day and disappeared at the third day. There was no severe pain, huge swelling, suppuration or mobility detected during the time of evaluation. All prosthetic restoration applied at 10 weeks post implant placement, clinical assessment showed good stability without any mobility and no signs of implantitis. Also, ringed sound listened with percussion in all cases after 10 weeks, except in 2 patients ( 2 implant), the sound and osseointegration were good at 6 months post implant insertion.

In one patient, has bridge on 2 implants, the patient complained of lateral periodontal abscess of one of them at one year post implant insertion. Probing depth in this patient was $4 \mathrm{~mm}$ and has buccal bone resorption (DIB - 4mm), in addition, implantitis and suppuration were observed. Antibiotic administrated and irrigation of peri-implant pocket with chlorhexidine $0.2 \%$, three times daily for 3 days. Signs of implantitis were disappeared within 4 days and follow- up was continued without recurrence. Except aforementioned observations, the patients were satisfied with implants procedures, according to Visual Analoge Scale (VAS) questionnaire and clinical parameters. Three patients missed at 6 months post prosthetic insertion, with good osseointegration and satisfied permanent restoration. The other implants, showed clinical stability without signs of infection or mobility (Fig.2).

The most frequent site of immediate implants were in the esthetic zone 40(72.73\%) in addition to 15 (27.27) inserted in premolar region (Tab.2). The implants were evaluated clinically and radiographically after final prosthesis, up to 6 months and once yearly for 4 years, as the following;

1. Implant stability, as afore-mentioned, incomplete stability observed in 2 cases only, at 10 weeks post implant insertion. All other implants, were stable and none of them lost osseointegration. No mobility was detected and peri-implant tissues were free of inflammation. The average values of stability (ISQ) measured with Osstell after attachment of transductor (Smart beg) to implant fixture. 


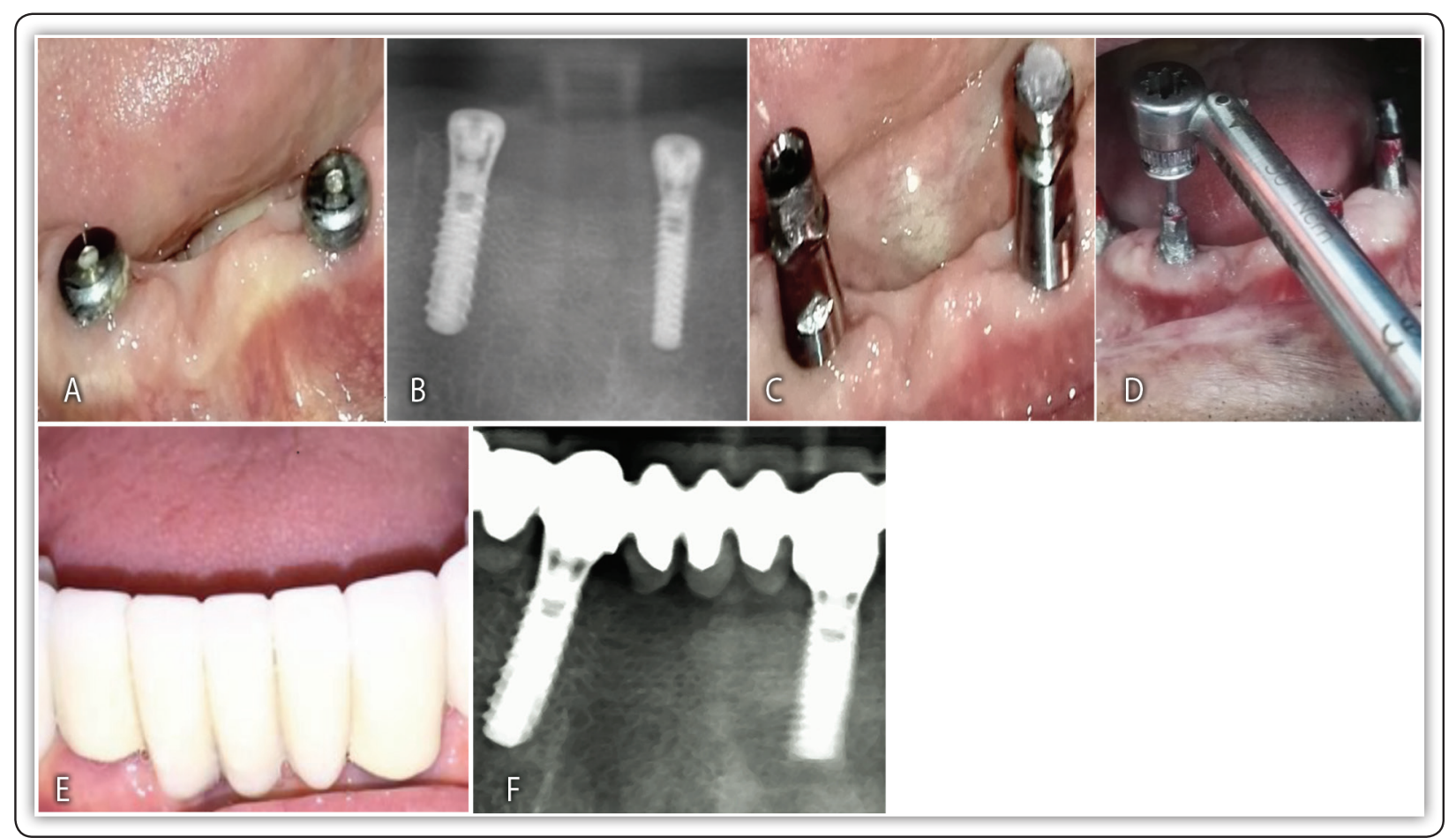

Fig (2) Showing; Photograph and x-ray of canine teeth after 10 weeks of implant inseertion (A\&B), abutment application and its reduction and seating torque at $35 \mathrm{ncm}(\mathrm{C} \& D)$, Permanent restoration \& its $\mathrm{x}$-ray $(\mathrm{E} \& \mathrm{~F})$.

The mean values in male patients, which measured immediately (0-day) and at 10 weeks post implant insertion, were; $69.3 \pm 2.88$ and $66.8 \pm 6.94$ respectively. While in female patients, the value were $70.3 \pm 2.36$ and $68.7 \pm 3.86$. According sex and age, there was no significant statistical difference, in the value of ISQ in whole time of evaluation $(\mathrm{P}=0.05)$ (Tab.4).

TABLE (4). Showing; ISQ measurement at 0 day and 10 weeks after implant insertion in male and female patients.

\begin{tabular}{|l|l|c|c|}
\hline Factor & Categories & 0 day & 10 weeks \\
\hline \multirow{2}{*}{ Sex } & Male & $69.3 \pm 2.88$ & $66.8 \pm 6.94$ \\
& Female & $70.3 \pm 2.36$ & $68.7 \pm 3.86$ \\
\hline \multirow{3}{*}{ Age, years } & $<36$ & $68.6 \pm 3.17$ & $65.0 \pm 8.17$ \\
& $36-45$ & $70.4 \pm 2.46$ & $70.1 \pm 2.42$ \\
& $>45$ & $70.1 \pm 2.03$ & $67.5 \pm 4.79$ \\
\hline
\end{tabular}

Means value \pm standard deviations without statistical significant difference $(P=0.05)$

\section{Periapical radiographs and CBCT}

A. Bone density increased gradually with the time of the study. Bone density in male and female patients were $3094 \pm 836$ and $3612 \pm 662$ respectively at 1 week post implant insertion. These values increased gradually to $4418 \pm 629$ and $4409 \pm 775$ at 4 years post implant insertion. However, there were no significant differences between bone density at different whole times of implantation between male and female or at patients different ages (Fig.3 \& Tab. 5).

Periapical views showed good position of implants and there were no signs of peri-implant radiolucencies. At alveolar crest ridge, the space between implant and bone decreased in horizontal width gradually after implant insertion, while the height of crestal bone was nearly equal (Fig.4). The distance between implant shoulder and first observed bone contact (DIB) ranged from $2.68 \pm 0.57 \mathrm{~mm}$ at 1 day to $2.25 \pm 0.46 \mathrm{~mm}$ at 4 years after implant insertion. However, there were no statistical significant differences ( $\mathrm{P}>0.05)$ (Fig.4 \& Tab. 6). 


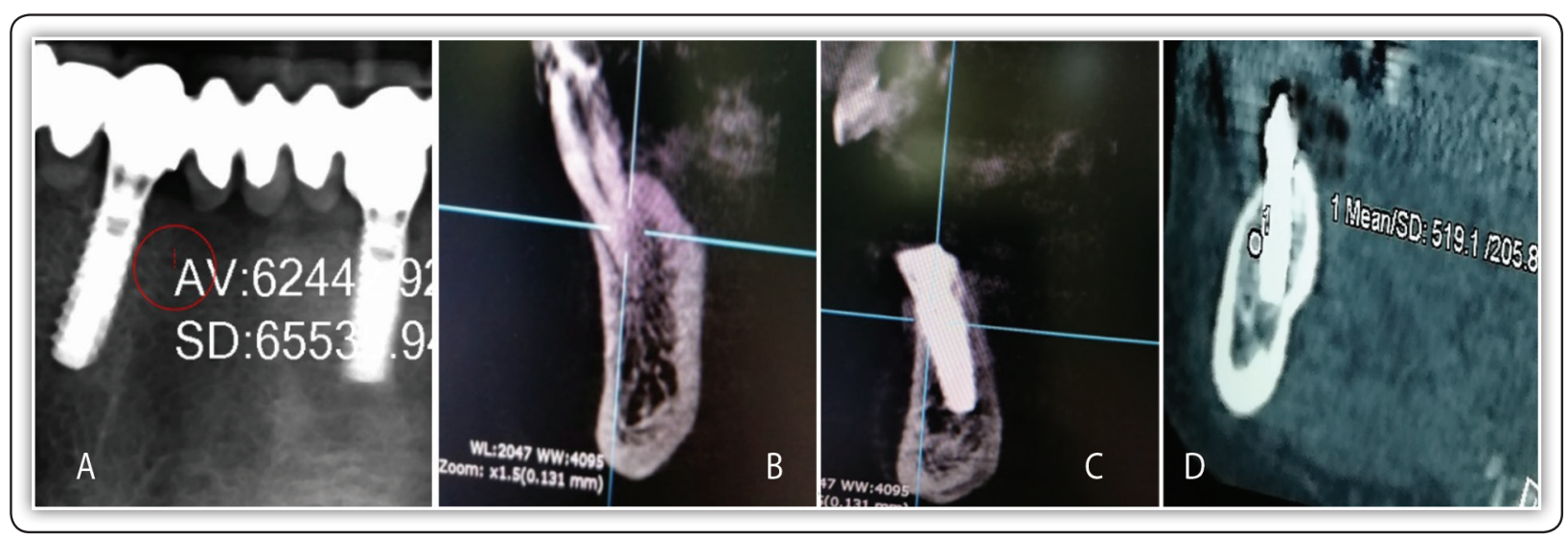

FIG (3) Periapical radiographs \& CBCT showing; good healing without bone resorption and density at ROI

TABLE (5).Showing mean values of bone density at region of interest ( ROI) in male and female patients.

\begin{tabular}{|c|c|c|c|c|c|c|}
\hline Factor & Categories & 1 week & 10 weeks & 6 months & 1 year & 4 years \\
\hline \multirow{2}{*}{ Sex } & Male & $3094 \pm 836$ & $3339 \pm 869$ & $4059 \pm 769$ & $4302 \pm 691$ & $4418 \pm 629$ \\
& Female & $3612 \pm 662$ & $3976 \pm 628$ & $4361 \pm 543$ & $4580 \pm 486$ & $4409 \pm 775$ \\
\hline
\end{tabular}

B. Distance between implant shoulder and the first bone-implant contact (DIB)

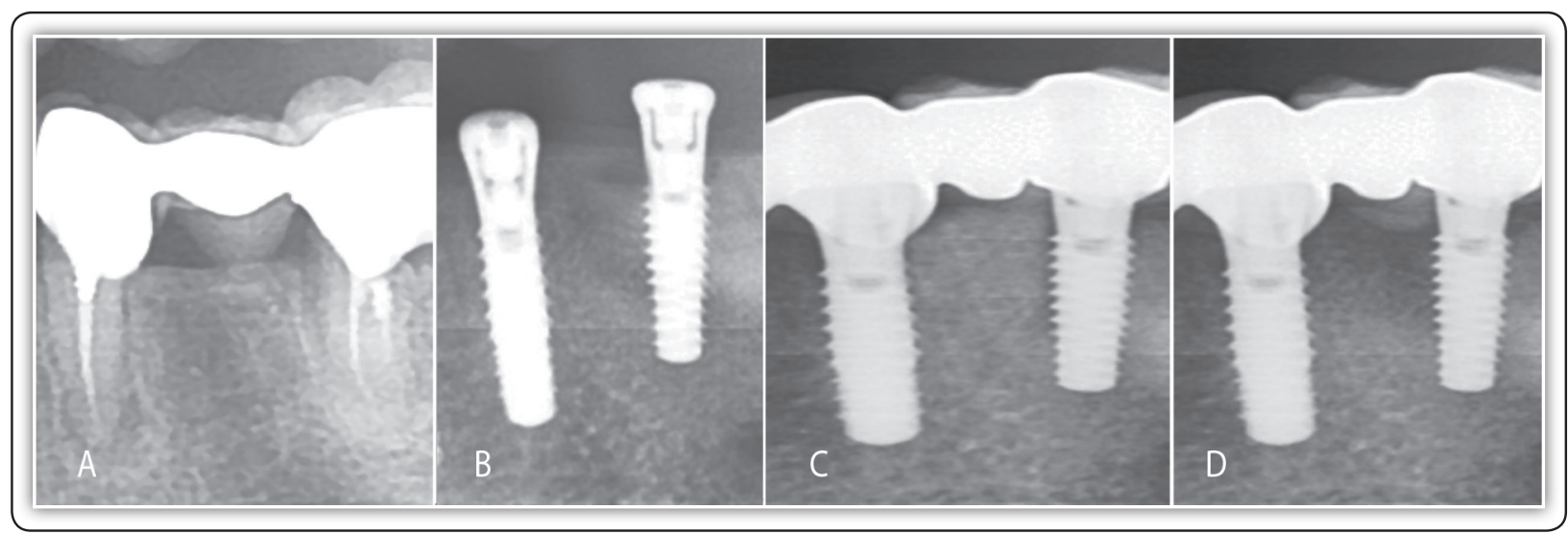

FIG (4) Showing; Pre-operative periapical radiographs (A), 10 weeks post implant insertion (B), one y.(C) and 4 years with bone resorption about $0.5 \mathrm{~mm}$ at ridge crest(D).

TABLE (6) showing mean values of distance between the implant shoulder and the first bone-implant contact (DIB) after implant insertion in male and female patients.

\begin{tabular}{|c|c|c|c|c|c|c|}
\hline Factor & Categories & 1 day & 10 weeks & 6 months & 1 year & 4 year \\
\hline \multirow{2}{*}{ Sex } & Male & $2.62 .68 \pm 0.57$ & $2.36 \pm 0.47$ & $1.75 \pm 0.42$ & $1.97 \pm 0.42$ & $2.25 \pm 0.46$ \\
& Female & $2.82 .86 \pm 0.59$ & $2.58 \pm 0.63$ & $1.96 \pm 0.56$ & $2.18 \pm .59$ & $2.38 \pm 0.52$ \\
\hline
\end{tabular}




\section{Clinical evaluation}

A. Probing depth (PD): The mean value of PPD in male patients were $1.80 \pm 0.61 \mathrm{~mm}$. at 10 weeks, which decreased to $1.23 \pm 0.6$ and $1.46 \pm 0.55 \mathrm{~mm}$. at 6 months and 1 y.P.O. This value increased to $1.70 \pm 0.55$ at 4 y. P.O. Statistically there was no significant difference between the mean values of probing depth according age and sex of the patients, throughout the study period. (Tab. 7 ).

B. Distance between implant shoulder and mucosa (DIM): The implant placed deep under the mucosa during surgery to avoid or reduce gingival recession. So that, the distances between implant and mucosa was positive from 10 weeks to 1 year, which ranged from $0.74 \pm$ 0.74 to $0.20 \pm 0.63$ respectively. This value decreased to negative $-027 \pm 0.39$ at 4 y P.O. Differences between male and female patients were not statistically significant $(\mathrm{P}>0.05)$ at evaluation times (Tab. 8 ).
C. Plaque index (PLI); in this study, a concentrated instruction was given to patient about maintenance of oral hygiene via brushing, mouth wash and dentist visit for scaling and cleaning. Clinically, the health of peri-implant tissues was good without calculus stagnation, except one patient had poor oral hygiene and suppuration in one implant. This patient treated with antibiotic, subgengival irrigation and oral hygiene maintenance. At 10 weeks P.O., PLI score of 0 was reported in $38 \%$ of the patients, score of 1 was $48 \%$ while score of 2 was $14 \%$ of patients. This score decreased at 6 months and at $1 \mathrm{y}$, then increased at $4 \mathrm{y}$. P.O. The medians (ranges), in male patients were; 1(2) at 10 weeks and 4 years, in addition to 1(3) at 6 months and 1 year P.O. In female patients, the medians (range) were 1(2) at 10 weeks, 0(3) at 6 months, 1(2) at one y. and 1(2) at 4 year P.O. However, no statistical significant differences were found (Tab. 9 \& Fig.5).

TABLE (7) Showing; The mean value of probing depth ( $\mathrm{mm})$ in four surfaces after implant insertion

\begin{tabular}{|c|c|c|c|c|}
\hline Categories & 10 weeks & 6 months & 1 year & 4 years \\
\hline Male & $1.80 \pm 0.61$ & $1.23 \pm 0.60$ & $1.46 \pm 0.55$ & $1.70 \pm 0.55$ \\
Female & $1.60 \pm 0.55$ & $1.05 \pm 0.46$ & $1.33 \pm 0.34$ & $1.53 \pm 0.26$ \\
\hline
\end{tabular}

Means values \pm standard deviations in male and female patients within times of evaluation without statistical significant difference $(P=0.05)$.

TABLE (8) Showing; Distance ( $\mathrm{mm}$ ) between implant shoulder and mucosa according sex of patients.

\begin{tabular}{|c|c|c|c|c|c|}
\hline Factor & Categories & 10 weeks & 6 months & 1 year & 4 years \\
\hline \multirow{2}{*}{ Sex } & Male & $0.74 \pm 0.74$ & $0.30 \pm 0.22$ & $0.20 \pm 0.63$ & $-0.27 \pm 0.39$ \\
& Female & $0.60 \pm 0.50$ & $0.28 \pm 0.25$ & $-0.05 \pm 0.69$ & $-0.28 \pm 0.53$ \\
\hline
\end{tabular}

Means value \pm standard deviations in male and female patients without significant difference $(P=0.05)$.

TABLE (9) Showing; Median value (Range) of Plaque index (PLI), according sex and age of the patients at the time of study

\begin{tabular}{|c|c|c|c|c|c|}
\hline Factor & Categories & 10 weeks & 6 months & 1 year & 4 years \\
\hline \multirow{2}{*}{ Sex } & Male & $1(2)$ & $1(3)$ & $1(3)$ & $1(2)$ \\
& Female & $1(2)$ & $0(3)$ & $1(2)$ & $1(1)$ \\
\hline
\end{tabular}

There were no statistically differentce, where $P=0.05$. Pairwise comparisons were conducted using MannWhitney U test (2 groups) or Kruskal-Wallis test then Dunn's test (>2 groups). 


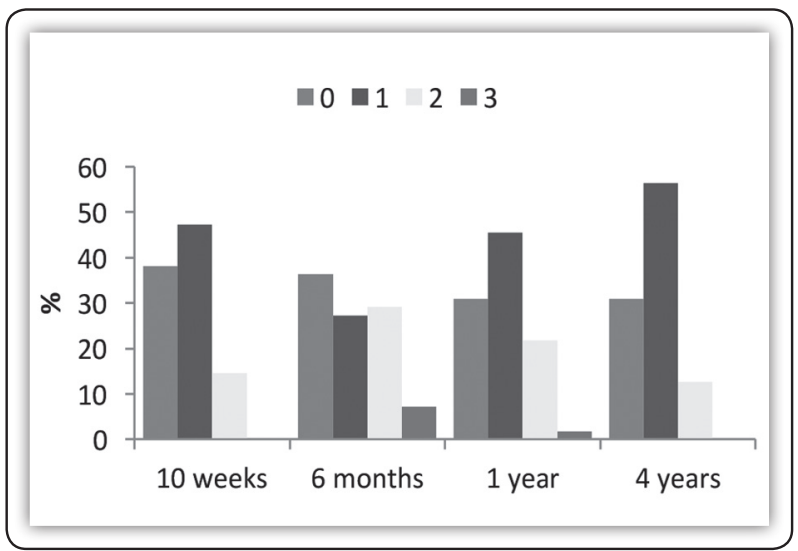

FIG (5) Showing; Distribution of Plaque index scores in \% by the time after implant insertion

D. Bleeding index (BI): The medians (ranges), in male patients were; 1(2) at whole time of evaluation. In female patients, the medians (range) were $0(2)$ at 10 weeks and 4 years, while median (range) of 1(2) was observed at 6 months and one y. post implant insertion. Score of 0 was recorded in $45 \%$ of the patients, score of 1 was in $44 \%$, while score of 2 was in $11 \%$ of patients at 10 weeks after operation. BI score of 1 decreased gradually at $6 \mathrm{~m}$. and $4 \mathrm{y}$. There were no signs of infection, suppuration or excessive bleeding in all implants. However, there were no statistical significant differences obtained between males and females and between stages after implantation (Tab.10 \& Fig. 6).

Tab. 10. Showing; Medians (Range) of Bleeding index (BI) in male and female patients at whole time after implant insertion.

\begin{tabular}{|c|c|c|c|c|c|}
\hline Factor & Categories & 10 weeks & 6 months & 1 year & 4 years \\
\hline \multirow{2}{*}{ Sex } & Male & $1(2)$ & $1(2)$ & $1(2)$ & $1(2)$ \\
& Female & $0(2)$ & $1(2)$ & $1(2)$ & $0(2)$ \\
\hline
\end{tabular}

Subcategories within gender and age were not significantly different $(P=0.05)$. Pairwise comparisons were conducted using Mann-Whitney U test (2 groups) or Kruskal-Wallis test then Dunn's test ( $>2$ groups).

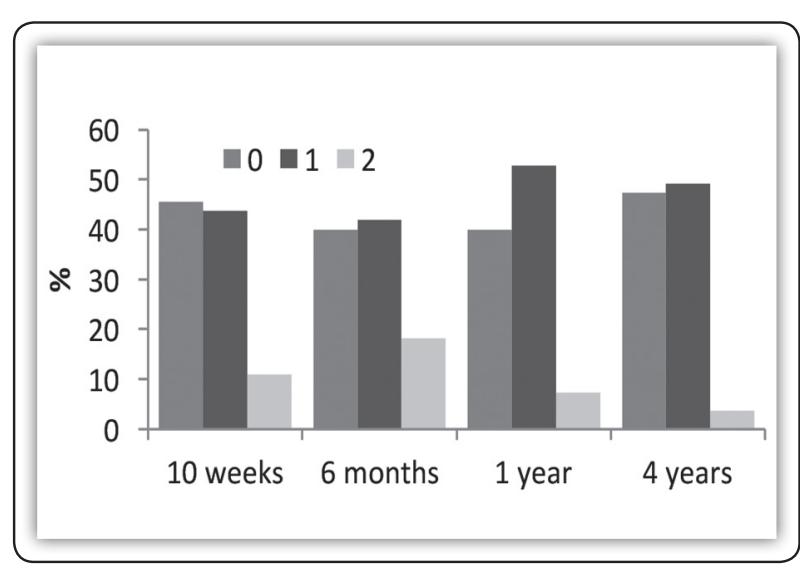

FIG (6) Showing;Distribution of bleeding index scores by stage after implant insertion

\section{DISCUSSION}

Immediate implant placement is a good option to restore extracted teeth with minimally invasive surgical technique. This technique has several advantages such as; reductions in the number of surgical interventions and complications, a shorter treatment time and ideal three dimensional implant positioning ${ }^{(23)}$ Post-operative complication such as severe pain and huge swelling were not observed at whole time of evaluation. The patients complained of mild to moderate pain at first day of implant insertion. This pain decreased at the second day and disappeared at third day in all cases of the present study. This may be due immediate implant insertion with flapless operation ${ }^{(24-25)}$

Implant failure may occur early at 3 to 5 months after implant insertion. This failure may occue due to improper surgical technique or heat generation, infection and lack of primary stability, in addition to improper load of mastication force ${ }^{(22)}$ No failure or mobility were reported in the present study. This might be due to applied proper atraumatic extraction with aseptic surgical technique under good cooling, good primary stability and good oral hygiene.

Post-operative assessment was done in the present study to assess implant stability and tissue integration with clinical and radiographic evaluation 
at whole time of study. Implant stability was assessed with resonance frequency analysis (RFA), seating torque and percussion sound auscultation. RFA provides objective and reliable evaluation of lateral mobility by measurement of an Implant Stability Quotient (ISQ) ${ }^{(28,29)}$. In the present study, the mean values for primary and secondary stability of the implant were $69.7 \pm 2.72$ and $67.5 \pm 6.03$, immediately and at 10 weeks post implant insertion respectively. These values were similar to each other, may be due to high insertion torque and good preparation of the implant site. The time of implant integration in our study was 10 weeks, thus stability of the implant fixture has been achieved without any mobility or signs of implantitis. In the study of Turkyilmaz and McGlumphy ${ }^{(30)}$ they reported that successful implants had mean ISQ value of 62.6 compared to value of 54.9 in failed implants. Also, Seong et $\mathrm{al}^{(31)}$, suggested that the implant should be left to heal without loading for 3 months if ISQ value of 49. After one year of stability and loading, there was no significant for measuring the ISQ values of implants ${ }^{(32)}$.

In the present study, seating torque was obtained at $35 \mathrm{Ncm}$ and ringed good sound was auscultated with percussion in all implants, except 2 cases. In these 2 cases, ISQ was 45 and sound was dull, which improved and implant osseointegrated at 6 months. Long time for osseointegration in these cases may be due to extensive curettage of the periapical pathosis. Seating torque and percussion results were concomitant with ISQ results and suggested success of our measurements in implant evaluation in agreement with Mistry et $\mathrm{al}^{(33)}$. Implant tapping with mirror handle and ringing tone sound indicating good osseointegration, while dull sound refers to bad osseointegration ${ }^{(29)}$.

Digital standardized radiograph and CBCT were done, in this study to determine bone density and distance between the implant shoulder and the first crestal bone height (DIB). Such measurements were reliable when compared with each other.
About 0.5 to $1 \mathrm{~mm}$ crestal bone height resorption, was observed during healing period, in agreement with other study ${ }^{(37)}$. Standardized radiographic procedures were applied based upon a right-angle with a paralleling technique using a rigid film-holder $\left(90^{\circ} \text { angulation }\right)^{(34,35)}$. So that, distortion and angulation errors were decreased, in addition, bone density and per-implant crestal bone levels can be identified $^{(36)}$. Also, one patient wearing bridge on 2 implants in the present study, complained of lateral periodontal abscess of one of them. In addition, implantitis with suppuration and buccal bone resorption (DIB, $4 \mathrm{~mm}$ ) with probing pocket depth $(4 \mathrm{~mm})$ were detected. This patient had bad oral hygiene, treated with antibiotic administration and irrigation of peri-implant pocket with chlorhexidine $0.2 \%$. A peri-implant radiolucency with crestal bone loss can be detected particularly in the patients with poor oral hygiene and aggressive periodontitis ${ }^{(38)}$.

Depth of implant placement and gingival biotypes, must be considered in order to minimize tissue resorption and crestal bone loss. These may also be an important factor in determining the implant stability and peri-implant mucosa. In the present study, patient selected with thick gingival mucosa and implant applied deeply. So that, the peri-implant cervical bone stability around implant neck and resorption decreasing were demonstrated in agreement with other study ${ }^{(39)}$

Clinical parameters of plaque index, (PLI), bleeding index (BI), probing depth (PD) and distance between implant shoulder and mucosal margin (DIM) are good parameter for care evaluation ${ }^{(40,41)}$ Aforementioned parameters were used to evaluate and assess of peri-implant soft tissue changes ${ }^{(42-43)}$ and underlying bone healing ${ }^{(44)}$. So that, we used in the present study to evaluate of the success of implant.

In the present study, the mean value of PLI, were 0 and 1 in $38 \%$ and $48 \%$ of the patients respectively. These scores referred to good oral hygiene, in 
agreement with another studies ${ }^{(42,45)}$ Score of 2 was $14 \%$ only, this scores decreased at 6 months and at $1 \mathrm{y}$, then increased at $4 \mathrm{y}$. P.O. This result may be due to a concentrated instruction which given to patient about maintenance of oral hygiene via brushing, mouth wash and dentist visit for scaling and cleaning. Clinically, the health of peri-implant tissues was good without calculus stagnation. The implant placed deep under the mucosa during surgery, in the present study, to avoid and decrease gingival recession. So that, the distances between implant and mucosa were positive from 10 weeks to 1 year. DIM was increased to negative value of $-027 \pm 0.39$ at $4 \mathrm{y}$. This value was good results in agreement with other study, who demonstrated, the thick gingiva usually was less subject to gingival recession than thin biotype gingiva following surgical manipulation ${ }^{(45)}$.

Probing depth increasing is one of important cause of implant failure ${ }^{(27,41)}$. PD in this study in agreement with another studies ${ }^{(36,45)}$, were ranged from $1.80 \pm 0.61 \mathrm{~mm}$, at 10 weeks, which decreased at 6 months and $1 \mathrm{y}$. after implant insertion. This value was increased in view patients at 4 y. P.O. This may be due to crestal bone resorption that occurred in these patients ${ }^{(46)}$

Based on this study, it can be stated that an immediate implants are related to reducing crestal bone resorption and decreasing overlying mucosal recession. Furthermore, this type of implant with flapless operation is a good challenge for implant application and success, aided in implant osseointegration, and increases patient satisfaction.

\section{REFERENCES}

1. Lang NP, Pun PL, Lau KY, Li KY, Wong MC. A systemic review of survival and success rates of implants placed immediately into fresh extraction sockets after at least 1 year. Clin Oral Impl Res 2012; 23: 39-46.

2. Wilson TG, Buser D. Timing of anterior implant placement post-extraction: immediate versus early placement. Clin Advan in Periodont 2011;1:61-76.
3. Sanz M, Cecchinato D, Ferrus J, Pjetursson EB, Lang NP, Lindhe J. A prospective, randomized-controlled clinical trial to evaluate bone preservation using implants with different geometry placed into extraction sockets in the maxilla. Clin Oral Impl Res 2009;21:13-21.

4. Hall JAG, Payne A, Purton DG, Duncan WJ, De Silva RK. Immediately restored, Single- Tapered Implants in the anterior maxilla: prosthodontic and aesthetic outcomes after 1 year. Clinical Implant Dentistry and Related Research 2007;1:34-45.

5. Jung D,Yoon H. Clinical and retrospective evaluation of 4.1-or $4.3 \mathrm{~mm}$-dimeter implant placed immediately in the molar region: A preliminary study. J Oral Maxillofac Surg 2016;74:489-96.

6. Ortega-Martinez J, Perez-Pascual T, Marequal-Bueno S herandez-Alfaro F, Ferres-Padro E. Immediate implants following tooth extraction. A systemic review. Med Oral Path Oral Cir Bucal 2012; 17: 251-61.

7. Branemark P. I, Hansoon B.O. Adell R, Breine U, lindstrom J, Hallene O, Ohman A. Osseointegrated implant in the treatment of the edentulous jaw. Experience from a 10year period. Scand J Plast Reconst Surg 1977;11:16-22.

8. Altitas NY, Takesen F, Bagis B, Baltacioglu E, Cezairli B, Senel FC. Immediate implant placement in fresh sockets versus implant placement in healed bone for full-arch fixed prostheses with conventional loading. Internat J Oral Maxillofac Surg 2016;45:226-31.

9. Soydan SS, Cubuk S, Oguz Y, Ukan S. Are success and survival rates of early implant placement higher than immediate implant placement. Int J Maxillofac Surg 2013;42:511-15.

10. Brown SDK, Payne AGT. Immediately restored single implants in the aesthetic zone of the maxilla using a novel design: 1-year report. Clin Oral Implant Res 2011;22: 445-54.

11. Moraschini V, Prto Barboza E. Immediate versus conventional loaded single implants in the posterior mandible; a meta-analysis of randomized controlled trials. Internat J Oral Maxillofac Surg 2016;45:85-92.

12. Mobelli A, Van-Osten M, Schurch E, Lang N. The microbiota associated with successful or failing osseointegrated titanium implants. Oral Micro Immun 1987;2:145-51.

13. Buser D, Wittneben J, Bornstein MM, Grutter L, Chappuis V, Belser UC. Stability of contour augmentation and esthetic out-comes of implant-supported single crowns in the esthetic zone: 3 -years results of a prospective study 
with early implant placement post extraction. J Periodontol 2011;82:342-49.

14. Buser D1, Mericske-Stern R, Bernard JP, Behneke A, Behneke N, Hirt HP, Belser UC, Lang NP. Long-term evaluation of non-submerged ITI implants. Part 1: 8-year life table analysis of a prospective multi-center study with 2359 implants. Clin Oral Imp Res. 1997; 8:161-72.

15. Cordaro L, Torsello F, Roccuzzo M. Clinical outcome of submerged vs. non-submerged implants placed in fresh extraction sockets. Clin Oral Implants Res 2009; 20:1307-13.

16. Evans CDJ, Chen ST. Esthetic outcomes of immediate implant placements. Clin Oral Impl Res 2008;19:73-80.

17. Abrahamsson I, Berglundh T, Moon I-S, Lindhe J. Submerged and non-submerged titanium implants Peri-implant tissues at submerged and non-submerged titanium implants. J Clin Periodontol 1999; 26: 600-07.

18. Chen ST, Darby IB, Reynolds EC. A prospective clinical study of non-submerged immediate implants: clinical outcomes and esthetic results. Clin Oral Implants Res 2007; 18: 552-62.

19. Buser D, Weber H B, Lang N P. Tissue integration of nonsubmerged implants, 1-year of prospectivs study with 100 ITI hollow cylinder and hollow-screw implants. Clin Oral Imp Res. 1990;1: 33-40.

20. Sanz I, Garcia-Gargallo M, Herrera D, Martin C, Figuero E. Surgical protocols for early implant placement in postex-traction sockets: a systematic review. Clinical Oral Implant Research 2012;23:67-79.

21. Veltri M, Balleri P, Ferrari M. Influence of Transducer Orientation on Osstell TM Stability Measurements of Osseointegrated Implants. Clin Impl Dent Relat Res 2007; 9: 60-64.

22. Jeffcoat M K, Williams R C. Relationship between linear and area measurements of radiographic bone levels utilizing simpe computerized techniques. J Dent Res 1984;19:191-98

23. Becker W. Immediate implant placement: treatment planning and surgical steps for successful outcomes. Br Dent J 2006; 201: 199-205.

24. Bayounis AM, Alzoman HA, Jansen JA, Babay N. Healing of peri-implant tissues after flapless and flapped implant installation. J Clin Periodontol 2011;38:754-61.

25. Liamas-moteagudo O, Girbes-Ballester P, Vina-Almunia J, Penarrocha-Oltra D, Penarrocha-diago M. Clinical parameters of implant placed in healed sites using flapped and flapless techniques: A systemic review. Med Oral Oral Pat Cir Bucal 2017; 1: 572-81.

26. Polizzi G, Grunder U, Goene R et al. Immediate and delayed implant placement into extraction sockets: a 5-years report. Clin Implant Dent Relat Res 2003;5:37-46.

27. Evian CI, Emling R, Rosenberg ES. Retrospective analysis of implant survival and the influence of periodontal disease and immediate placement on long-term results. Int J Oral Maxillofac Imp. 2004;19:393-98.

28. Granic, Katanec D, Boras V, Susic M, Juric I, Gabric D. Implant stability comparison of immediate and delayed maxillary implant placement by use of resonance frequency analysis- a clinical study. Acta Clin Croat 2015; 54:1-6

29. Sennerby L, Meredith N. Implant stability measurements using resonance frequency analysis: biological and biomechanical aspects and clinical implications. Periodontol 2000 2008;47:51-66

30. Turkyilmaz I, Mc Glumph y EA. Influence of bone density on implant stability parameters and implant success: a retrospective clinical study. BMC Oral Health. 2008;8:32-37.

31. Seong WJ, Holte JE, Holtan JR, Olin PS, Hodges JS, Ko CC. Initial stability measurement of dental implants placed in different anatomical regions of fresh human cadaver jawbone. J Prosthet Dent. 2008;99 :425-34.

32. Balleri P, Cozzolino A, Ghelli L, Momicchioli G, Varriale A. Stability measurements of osseointegrated implants using Osstell TM in partially edentulous jaws after 1 year of loading: a pilot study. Clin Implants Dent Relat Res 2002; 4:128-32.

33. Mistry G, Shetty O, shetty S, raghuwar D, Singh R. Measuring implant stability: A review of different methods $\mathrm{J}$ Dent Impl 2014;4:165-69.

34. Benkow HH. A new principle for clinical roentgenographic tooth measurement. Odontologisk Tidskr 1960; 68:423-29.

35. Venuleo C, Chuang S, Weed M, Dibart S. Long term bone level stability on Short Implants:

36. A radiographic follow up study. J Maxillofac Oral Surg 2008; 7:340-45.

37. Adell R, Eriksson B, Lekholm U, Branemark PI, Jemt T. A long-term follow-up study of osseointegrated implants in the treatment of totally edentulous jaws. Int J Oral Maxillofac Implants 1990;5:347- 59.

38. Hanggi M, Hänggi D, Schoolfield J, Meyer J, Cochran D, Hermann J.Crestal bone changes around titanium Implants. Part I: A retrospective radiographic evaluation in 
humans comparing two non-submerged implant designs with different machined collar lengths J Periodontol 2005; 76: 791-802.

39. Botticelli D, Berglundh T, Lindhe J. Hard-tissue alterations following immediate implant placement in extraction sites. J Clin Periodontol 2004; 31: 820-28.

40. Benn DK. A review of the reliability of radiographic measurements in estimating alveolar bone changes. J Clin Periodontol 1990;17:14-21.

41. Hermann JS, Buser D, Schenk RK, Higginbottom FL, Cochran DL. Biologic width around titanium implants. A physiologically formed and stable dimension over time. Clin Oral Implants Res 2000;11:1-11.

42. Mombelli A, Lang NP. Clinical parameters for the evaluation of dental implants. Periodontol 2000 1994;4:81-86.

43. Mombelli A, Lang NP. The diagnosis and treatment of peri-implantitis. Periodontol 2000 1998;17:63-76.
44. Buser D, Belser UC. Optimizing esthetics for implant restorations in the anterior maxilla: anatomical and surgical considerations. Int $\mathbf{J}$ of Oral and Maxillofac Impl 2004; 19:43-61

45. Botticelli D, Berglundh T, Lindhe J. Hard-tissue alterations following immediate implant placement in extraction sites. J Clin Periodontol 2004; 31: 820-28.

46. Belser UC, Grutter L, Vailati F, Bornstein MM, Weber HP $\&$ Buser D. Outcome evaluation of early placed maxillary anterior single-tooth implants using objective esthetic criteria: a cross-sectional, retrospective study in 45 patients with a 2-to-4 year follow up using pink and white esthetic scores. J Periodontol 2009;80:140-51.

47. Moraschini V, Poubel LA, Ferreira VF, Barboza ED. Evaluation of survival and success rates of dental implants reported in longitudinal studies with a folloew-up period of at least 10 years; a systemic review. Int J Oral Maxillofac Surg 2015; 44: 377-88. 
